\title{
CRITERIOS PARA EL INICIO DE LA CONVECCIÓN Y LA FORMACIÓN DE ESTRUCTURAS COHERENTES SOBRE CAMAGÜEY, CUBA
}

\author{
NIVIAN QUINTANA RODRÍGUEZ, MAIBYS SIERRA LORENZO E MARIO CARNESOLTAS CALVO
}

\author{
Centro de Física de la Atmosfera, Instituto de Meteorología, La Habana, Cuba \\ nivian.quintana@insmet.cu, maibys.lorenzo@insmet.cu, mario.carnesoltas@insmet.cu
}

Recibido Diciembre 2009 - Aceptado Enero 2010

\begin{abstract}
RESUMO
São apresentados os resultados de uma investigação sobre o processo de convecção de Rayleigh Bénard partindo do cálculo dos números adimensionais de Rayleigh $(R a)$ e de Richardson $(R i)$, com o objetivo de encontrar critérios que sejam representativos do disparo da convecção nas condições tropicais e insulares de Cuba. Os resultados são comparados com os obtidos empregando-se a técnica de ondeleta, e as observações de nebulosidade obtidas das imagens de satélites meteorológicos. Utilizaram-se as medições do mês de Junho do ano 2007 na torre de gradiente em Camagüey, e foram obtidos resultados como o número $R a$ crítico, $\left(R a=1.32 \times 10^{3}\right)$. A velocidade vertical positiva foi empregada como condição necessária para o disparo da convecção. Encontrou-se que o $R a$ é um parâmetro indicador do tipo de convecção que deve formar-se, enquanto que o $R i$ é um indicador de sua intensidade.
\end{abstract}

Palavras-chaves: convecção, estruturas coerentes

\begin{abstract}
CRITERIA FOR THE ONSET OF CONVECTION AND THE FORMATION OF COHERENT STRUCTURES OVER CAMAGUEY, CUBA

Results from an investigation on the physical process of Rayleigh-Bernard convection, based on the calculus of the dimensional Rayleigh $(R a)$ and Richardson $(R i)$ numbers, with the objective of finding criteria representative of the onset of convection in Cuba's tropical and insular conditions are shown. The obtained results are compared to those based on the Wavelets Technique and cloudiness derived from meteorological satellite images. Observations on June 2007 at Camagüey gradient Tower were used, and some results were derived, such as the critical $\left(R a=1.32 \times 10^{3}\right)$. Positive value of the vertical velocity was set as the necessary condition for the onset of convection. It was found that $R a$ is an indicator of the convection type that should form, whereas $R i$ is an indicator of its intensity.
\end{abstract}

Keywords: convection, coherent structures

\section{INTRODUCCIÓN}

La convección es uno de los procesos físicos más importantes que tiene lugar en la Capa Fronteriza Atmosférica (CFA) para las Ciencias Meteorológicas, ya que el mismo constituye el eslabón inicial de la larga y complicada cadena de eventos que se inician y desarrollan en la atmósfera, incluyendo desde la formación de una nube simple, hasta la manifestación de severidad más significativa en las tormentas locales severas; dígase la ocurrencia de tornados, granizos, aeroavalanchas, trombas marinas y más recientement e se incluyen las lluvias intensas. Una parte fundamental del mecanismo de la convección profunda que interviene en la generación de nubosidad convectiva y con presencia de TLS, es la interacción de estructuras denominadas Celdas de Rayleigh - Bénard (CRB) y Rollos Convectivos Horizontales (HCR) con fronteras de la mesoescala- $\beta$, asegurando el desarrollo de convección profunda cuando no esta presente algun otro fenómeno de escalas espaciales superiores (Fovel, 2004), tomando como ejemplo la interacción de HCR con el frente de briza de mar .

La Capa Fronteriza Atmosférica también conocida como Capa Limite Planetaria, se define como la sección o porción de un fluido, sea líquido o gas, que está en contacto con una superficie, sea sólida o líquida, donde tienen lugar importantes 
intercambios de momento, de calor o de masa entre ambos. Consecuentemente, en esta capa se observan variaciones bruscas de las propiedades del fluido, tales como la velocidad y la temperatura y durente 1 dia constituye el seno de la convección a escala local. La capa límite atmosférica desarrolla una estructura bien definida que evoluciona con el ciclo diurno (Stull, 1988). Las tres componentes principales de esta estructura son: la capa de mezcla, la capa residual y la capa estable nocturna. Además, dentro de la capa fronteriza atmosférica se define una capa más fina, cercana al suelo, que se denomina capa superficial atmosférica.

El comportamiento de la capa superficial atmosférica muestra una fuerte variación diurna; durante las horas de sol, se caracteriza por un gradiente superadiabático, un decrecimiento de la humedad con la altura y una gran cizalladura de viento, además, la turbulencia es de carácter térmico y mecánico (Buenestado, 2003). Por la noche, la capa superficial atmosférica se caracteriza por una fuerte estabilidad que impide los movimientos verticales de las partículas de aire, mostrando generalmente turbulencia de carácter mecánico exclusivamente.

Businger (1973) observó que la capa fronteriza nocturna presenta grandes diferencias entre los casos estables con turbulencia continua y los casos muy estables con turbulencia intermitente, y en concordancia con esto Malhi (1995), Oyha et al. (1997) y Mahrt et al. (1998), citados por Buenestado (2003), clasifican la capa fronteriza atmosférica estable en dos categorías extremas: la capa fronteriza muy estable y la capa fronteriza débilmente estable. La capa fronteriza débilmente estratificada estable sobre tierra normalmente ocurre con viento importante y/o cobertura nubosa, donde el enfriamiento de la superficie es relativamente débil y la turbulencia es más o menos continua (Zilitinkevich y Mironov, 1996). En contraste, la capa fronteriza muy estable se caracteriza por vientos débiles y cielos despejados, correspondiéndose con grandes enfriamientos radiativos de la superficie. En consecuencia, la turbulencia es débil e intermitente cerca del suelo, y quizás intermitente por capas. De hecho, la turbulencia puede ser menor cerca del suelo que en la cima de la capa de inversión superficial (Mahrt, 1999; Ohya et al., 1997).

Wilson y Schreiber (1986); Koch y Ray (1997) vinculan el origen de la convección a zonas de convergencia en la capa límite planetaria, sin embargo, al no poder localizar en ocasiones dichas zonas de convergencia en capas bajas, se ha asumido que los mecanismos de disparo pueden estar también elevados (Wilson y Roberts, 2004).

El análisis del inicio de la convección en un área determinada puede ser llevado a cabo utilizando diferentes tipos de datos y diferentes enfoques. Inicialmente se utilizaron las imágenes del canal visible de los satélites geoestacionarios para identificar los núcleos convectivos incipientes (Purdom,
1982) lo que se retoma con mucha frecuencia por no presentar inconveniencias en la obtención de esta información primaria.

Las estructuras coherentes se definen en general, como "sistemas organizados que dependen de los flujos externos para mantener su organización y para disipar los gradientes energéticos asociados a los procesos auto-organizados" (Schneider y Kay, 1995). Según Chandrasekhar (1961), "la transición en un flujo calentado por conducción-convección (celdas de Rayleigh-Bénard) es un llamativo ejemplo del surgimiento de una organización coherente en respuesta a una entrada de energía externa"

Las CRBs cerradas, surgen en un ambiente inestable con el viento en calma o muy débil, su base puede tomar sólo tres formas: triangular, cuadrada o hexagonal (Emanuel, 1994). Las formas de la base se refiere a que por el centro de una celda cerrada, el aire asciende verticalmente, mientras que las corrientes descendentes compensantes lo hacen por tres, cuatro o seis puntos situados a su alrededor. El vapor de agua que acompaña al aire que asciende, al traspasar el nivel de condensación, se condensa y aparece una nube fractocúmulos, luego un cúmulos $(\mathrm{Cu})$ humilis y hasta un cúmulo mediocris; los puntos por donde el aire desciende se mantienen despejados.

Por su parte, las CRBs abiertas aunque cumplen también las formas de sus bases, surgen en el seno de una corriente fría descendente que proviene de los topes de las nubes $\mathrm{Cu}$ en estado de disipación. La corriente descendente, al llegar a la superficie terrestre tiende a esparcirse en todas las direcciones, y en los bordes que forma en su avance horizontal, va levantado el aire caliente y por lo general húmedo, que se encontraba cerca de la superficie; De esta forma, mientras que en el centro de la celda quedan los restos del $\mathrm{Cu}$ disipado, o ya el aire claro, en los bordes aparecerán nuevas nubes $\mathrm{Cu}$, desde fracto $\mathrm{Cu}$ hasta $\mathrm{Cu}$ congestus, también en los vértices de un triángulo, un cuadrado o un hexágono, pero de mayores dimensiones en sus lados que en las celdas cerradas.

Los HCRs aparecen en las horas de la mañana, también debido al calentamiento de la superficie terrestre que provoca corrientes ascendentes por flotabilidad, pero se requiere que el viento no esté en calma y exista cizalladura vertical. Estas condiciones hacen que las corrientes ascendentes se desvíen de la vertical local y que las ramas laterales de las corrientes compensantes, lo hagan en el sentido del vector del viento medio en la capa, la resultante es la aparición de dos circulaciones contra-rotatorias una al lado de la otra, que descansan sobre la superficie de la tierra y con su eje principal a lo largo de dicho vector medio. El efecto de la cizalladura vertical es desviar a uno u otro lado la dirección del eje principal. A lo largo de dos ramas ascendentes contiguas aparecerán las nubes $\mathrm{frCu}, \mathrm{Cu}$ humilis y $\mathrm{Cu}$ mediocris, separadas a una distancia que depende, entre otros factores, de las propias corrientes descendentes de 
las nubes formadas. Los HCRs son los responsables de las llamadas "calles de nubes".

De acuerdo a la semejanza física (Fernández, 2001), "para que dos problemas fluido-mecánicos sean físicamente semejantes no es necesario que sean idénticos, sino que es suficiente que sean iguales todos los parámetros adimensionales que aparecen en las ecuaciones de Navier Stokes que los gobiernan y los que aparecen en las condiciones de contorno". Si se cumplen tales igualdades, la solución adimensional del problema es la misma para ambos. La solución física se obtiene luego retomando los cambios de variables hechos utilizando las magnitudes características de cada problema. Entre los aspectos prácticos más importantes de la semejanza física es que permite experimentar con modelos de una forma rigurosa, extrapolándose sin ambigüedad los resultados a la escala real.

Por tanto otra manera de resolver el problema es a partir del tratamiento de números adimensionales que expresen características del movimiento convectivo de un fluido determinado, o sea que relacionen las fuerzas que de una forma u otra intervienen en el proceso físico de la convección. Los números más utilizados en este tipo de problema son el número de Rayleigh $(R a)$, el número de Prandlt $(P r)$, el número de Grashof $(G r)$, el número de Reynolds $(R e)$ y el número de Richardson (Ri).

Debido al limitado conocimiento existente sobre los valores de los parámetros que intervienen en el inicio de la convección en las condiciones tropicales e insulares de Cuba, en el presente trabajo se plantean criterios para el inicio de la convección y la formación de estructuras coherentes, se parte del supuesto que teniendo los valores teóricos de ciertos números adimensionales para el inicio de la convección, sería posible (en conjunto con otras teorías), predecir las características de la nubosidad convectiva que pudiera desarrollarse posteriormente, y se daría un paso en el pronóstico de su ubicación más probable en escalas inferiores a la escala sinóptica.

El enfoque de este resultado es totalmente novedoso en Cuba puesto que no existen antecedentes de investigaciones sobre procesos físicos que ocurren en la atmósfera a esta escala temporal y espacial. El trabajo forma parte de un proyecto de investigación que realiza el Instituto de Meteorología (INSMET), dirigido a determinar las condiciones en las que se inicia y desarrolla la nubosidad convectiva sobre el territorio cubano.

\section{MATERIALES Y MÉTODOS}

\subsection{Características físicogeográficas dela región de estudio}

La torre de gradiente de Camagüey se encuentra ubicada en $\operatorname{los} 21,43^{\circ}$ de latitud $\mathrm{N}$ y los $77,92^{\circ}$ de longitud W, a $110 \mathrm{~m}$ sobre el nivel del mar en la provincia de Camagüey. La torre tiene una altura total de $219 \mathrm{~m}$, pero los instrumentos se encuentran en los niveles de 10, 30, 50 y 100 m. Fue montada sobre un relieve de llanura ondulada y ambiente semiurbano sobre un suelo medianamente arcilloso. La temperatura media anual de esta zona oscila entre $24^{\circ}$ y $26^{\circ} \mathrm{C}$ y humedad relativa entre el 75 y el $80 \%$. Se distinguen dos periodos en el año, uno lluvioso (de mayo a octubre) y uno poco lluvioso (de noviembre a abril).

El viento medio determinado durante un año de mediciones de la torre de gradiente de Camagüey es de $2.65,4.23,5.05,6.31 \mathrm{~m} / \mathrm{s}$ a $10,30,50$ y $100 \mathrm{~m}$ de altura respectivamente, (Roque, comunicación personal, 2008).

\subsection{Datos tomados en la investigación}

En la investigación se utilizaron los datos de temperatura y humedad relativa a 10 y $100 \mathrm{~m}$ de altura, la velocidad del viento a 10,30, 50,100 m, y la presión atmosférica a 10 metros, correspondiente al mes de junio de 2007. Esta torre de gradiente se seleccionó por la posibilidad de disponer de la información de la estación aerológica y de una estación meteorológica automática ubicada en el Centro Meteorológico e Camagüey, que permitiera corroborar los resultados en un futuro. Todos los datos están referidos a la hora del meridiano $75^{\circ} \mathrm{W}$.

En la descripción de la situación a escala sinóptica imperante los días escogidos, se emplearon los re-análisis de los mapas obtenidos del CDC de la NOAA. Los niveles seleccionados fueron 1000, 925, 850, 700, 500, 300 y $200 \mathrm{hPa}$, de las variables altura geopotencial, temperatura potencial y humedad relativa.

Con la finalidad de conocer la situación a escala sinóptica a la que se encontraba cada día de la muestra tomada y determinar así la influencia de las condiciones sinópticas en el inicio y desarrollo de la convección, se emplearon los re-análisis de los mapas obtenidos del CDC de la NOAA. Los niveles seleccionados fueron 1000, 925, 850, 700, 500, 300 y $200 \mathrm{hPa}$, de las variables altura geopotencial, temperatura potencial y humedad relativa. Para lograr comparaciones entre las características de la convección que se determinaran con los números adimensionales, y los diferentes patrones nubosos representativos de la condición que se pusiera de manifiesto en el momento de la observación, se tomaron las imágenes de la estación de satélite ubicada en Casa Blanca en la banda visible.

\subsection{Descripción de la metodología}

El método empleado para detectar los sistemas locales de convección organizada fue la comparación de los valores de los números adimensionales, con sus valores medios, relacionando las diferencias con la nubosidad convectiva detectada las imágenes de los satélites meteorológico en la banda visible, para los días y horas específicas. El método empleado para 
detectar las altas y las bajas concentraciones de vorticidad, fue la aplicación de la Transformada Wavelet Continua de una dimensión.

A continuación se relacionan los números adimensionales que se emplean en la investigación.

\section{i) Número de Rayleigh}

El número de Rayleigh $(R a)$ relaciona las fuerzas de flotabilidad con las fuerzas de viscosidad (en este caso las turbulentas). Numéricamente es igual al producto del número de Grashof $(G r)$ y el número de Prandtl $(P r)$.

El número de $R a$ es equivalente al número de Reynolds $(R e)$ para los flujos convectivos, y resulta una medida de la estabilidad del flujo para disturbios hidrodinámicos, por lo tanto sirve como indicador de la transición de régimen laminar a la convección turbulenta (Emanuel, 1994). y se define como:

$$
R a=\frac{g h^{3}\left(\frac{\Delta T}{T_{0}}\right)}{\kappa v}
$$

donde $h$ es la altura de la capa, $\kappa$ es el coeficiente de de difusión térmica, $v$ es el coeficiente de viscosidad dinámico, $\mathrm{T}_{0}$ es la temperatura inicial y $\Delta \mathrm{T}$ es la variación de temperatura en la capa.

El número de Grashof es la razón entre las fuerzas de flotabilidad y las fuerzas viscosas que se define como,

$$
G r=\frac{\rho^{2} \beta g h^{3}\left(T-T_{0}\right)}{\mu^{2}}
$$

En la cual $\rho$ es la densidad, $\beta$ es el coeficiente de expansión térmica, $\mu$ es coeficiente de viscosidad cinemático y $g$ la gravedad. Este número es fundamental en la descripción de los procesos convectivos, en esta investigación no fue necesario calcularlo por separado para determinar el número de Rayleigh, ya que al multiplicarlo por $\mathrm{Pr}_{t}$ se obtuvo una expresión más sencilla para este último.

El número de Prandtl, describe una propiedad del fluido y representa la importancia relativa que en ese fluido tienen dos fenómenos de transporte: la difusión viscosa o de cantidad de movimiento y la difusión de calor o energía. Sin embargo para el caso turbulento es una propiedad del flujo que depende de las coordenadas. En los gases el número de Prandtl es del orden de la unidad y para la atmósfera, según Sutton (1953), tiene un valor de alrededor de 0.7. En la Ecuación $3, c_{p}$ es el calor específico a presión constante

$$
\operatorname{Pr}=\frac{\mu c_{p}}{\kappa}
$$

El número de Reynolds, razón entre las fuerzas inerciales y las fuerzas viscosas. En la Ecuación 4, $V$ representa la velocidad del viento.

$$
\operatorname{Re}=\frac{\rho V h}{\mu}
$$

En mecánica de fluidos, a partir de cierto valor crítico de $R e_{c}$ se determina el régimen en que se encuentra el flujo (laminar o turbulento). Sin embargo, al igual que el número de Grashof, tampoco se requirió calcularlo de forma independiente para determinar el número de Richardson.

En el inicio de la convección y la posterior formación de las celdas y/o los rollos intervienen, tanto las fuerzas de flotabilidad como las fuerzas inerciales, por lo que para ello se empleó como número adimensional la razón sugerida por Byron, et al. (1960), entre los números adimensionales de Grashof y Reynolds al cuadrado (otra forma del número de Richardson) quienes plantearon que "cuando el valor de esta razón es grande significa que las fuerzas de flotabilidad son importantes en la determinación de las características del flujo”.

$$
R i=\frac{G r}{\operatorname{Re}^{2}}=\frac{-g h\left(\frac{T-T_{0}}{T_{0}}\right)}{\bar{V}^{2}}
$$

donde la velocidad del viento $V$ se tomó como el promedio de velocidades de los cuatro niveles que mide la torre, para evitar los casos donde la razón se indetermina con valores de velocidad nulo y que además refleje el flujo medio en todo el espesor de la capa, o sea

$$
V=\frac{V_{10}+V_{30}+V_{50}+V_{100}}{4}
$$

No obstante, también se utilizó la velocidad en el nivel de $10 \mathrm{~m}$ en lugar de la $V$ con la finalidad de determinar de forma más precisa el momento de inicio de la convección. El signo menos que aparece en la Ecuación 5 es totalmente convencional, y se hizo con el sólo objetivo de que los valores positivos de la diferencia de la temperatura coincidiera en los gráficos, con la parte superior del eje. También es necesario aclarar que el coeficiente de difusividad térmica, y la viscosidad, tanto dinámica como la cinemática en las Ecuaciones 3 y 4, se tomaron con los valores correspondientes a los procesos turbulentos y no a los procesos moleculares.

Este número ha sido muy utilizado como parámetro de estabilidad térmica en la capa superficial.

Los valores de los números adimensionales obtenidos se compararon con los resultados de la aplicación de la transformada continua de Wavelet a la formación de estructuras coherentes en la capa fronteriza atmosférica, a partir de los valores de la vorticidad. 


\section{ii) Cálculo de la velocidad vertical}

En este trabajo se tomó como condición necesaria para el inicio y existencia de la convección cuando $\omega>0$, y con esto se plantea entonces otra forma de resolver el problema que permita relacionar los términos analíticos con variables meteorológicas (como la temperatura), y que sea una función del tiempo, partiendo de la solución general de la ecuación diferencial de sexto orden que obtiene Sutton en 1952, tratando de resolver el sistemas de ecuaciones de Navier Stokes.

$$
\varpi_{1}(x, y, z, t)=G_{1}\left(z, \frac{\Delta T}{T_{0}}, t\right) f(x, y)
$$

En la cual $G_{1}\left(z, \frac{\Delta T}{T_{0}}, t\right)$ está en función de la altura (z), del tiempo (t) y de la variación temporal de la estabilidad vertical, tomada como la velocidad vertical a partir de integrar la fórmula de flotabilidad,

$$
\omega=g t\left(\frac{\Gamma-\gamma}{T}\right) \Delta z
$$

donde $g$ es la aceleración de la gravedad, $\Gamma$ es el gradiente adiabático seco, $V$ es el gradiente vertical de temperatura, $T$ es la temperatura en la base de la capa seleccionada y $\Delta z$ es el espesor de la capa. Por lo que la variación temporal del problema se incluye dentro de los términos de la ecuación que varían espacialmente ya que estas variables espaciales dependen de los cambios de la temperatura en el tiempo.

\subsection{Aplicación de la Transformada Wavelet Continua a la vorticidad}

De acuerdo a la representación de Helmholtz, todo campo vectorial $V$ se puede descomponer en una parte irrotacional y otra no divergente. La vorticidad es una medida de la rotación local del fluido, o el rotacional de la velocidad del fluido, que se expresa en coordenadas cartesianas como:

$$
\nabla \times V=\xi_{h 1}+\xi_{h 2}+\xi_{v}=\left(\frac{\partial w}{\partial y}-\frac{\partial v}{\partial z}\right) \vec{i}+\left(\frac{\partial u}{\partial z}-\frac{\partial w}{\partial x}\right) \vec{j}+\left(\frac{\partial v}{\partial x}-\frac{\partial u}{\partial y}\right) \vec{k}
$$

A partir del cálculo de $w$ por el método cinemático de la velocidad vertical (el cual se deduce de la ecuación de continuidad en coordenadas de presión), se utilizó la Ecuación 9 para calcular las dos componentes horizontales $\xi_{h 1} \xi_{h 2}$, y con ellas se determinó la vorticidad resultante.

Las funciones wavelet son una herramienta de localización en tiempo y frecuencia, es decir, permiten localizar o filtrar en un momento determinado cierta componente de frecuencia (Sierra,
2008). Precisamente por esta característica fueron seleccionadas para procesar los datos y localizar en tiempo y escala las CRBs y los HCRs presentes en el flujo turbulento atmosférico.

La Transformada Wavelet Continua de una función $f$ se define como la convolución de $f$ con la familia de la wavelet $\psi(t)$ : donde $a$ es el parámetro de escala y $b$ es el parámetro de traslación.

$$
\left(W_{\psi} f\right)(a, b)=\frac{1}{\sqrt{a}} \int_{-\infty}^{\infty} f(t) \overline{\left(\frac{t-b}{a}\right)} d t \quad f(t) \in L^{2}
$$

Para el estudio de campos turbulentos se utiliza la Ecuación 10 con una familia de wavelets de valores complejos, debido a que el módulo de los coeficientes wavelets permite el análisis de la evolución de la densidad de energía en tiempo y escala. En esta investigación fue utilizada la wavelet de Morlet,

$$
\psi(t)=\mathrm{e}^{i \xi_{\psi} t} \mathrm{e}^{-\left(|\mathrm{t}|^{2} / 2\right)}
$$

donde $\xi_{\psi}$ es el centro de soporte de la wavelet.

En la detección de las CRB y los HCRs se aplicó la transformada wavelet continua de una dimensión al campo de vorticidad del flujo, de manera que se distinguieran con claridad su localización temporal y su escala relativa. Además, con el módulo de los coeficientes de wavelet, se analizó el comportamiento temporal de la energía buscando patrones de intermitencia en su concentración.

Finalmente se realiza la comparación entre los valores de los números adimensionales con los resultados del análisis de la vorticidad aplicándole la transformada de Wavelet continua, asociándolos con las características de la nubosidad convectiva que se puede apreciar en las imágenes de satélite.

La herramienta utilizada para la implementación de todos los cálculo fue MATLAB versión 7.0 sobre Windows.

\section{ANÁLISIS Y DISCUSIÓN DE LOS RESULTADOS}

En este trabajo se realiza el estudio detallado del mes de junio de 2007, como ya se había mencionado, con el objetivo de caracterizar el inicio y desarrollo de la convección dentro de la capa fronteriza atmosférica, para ello se identificaron cuantos y cuales de los días presentaron situaciones sinópticas que son propicias para la ocurrencia de la convección local o sea que no existían sistemas a escalas sinóptica que fueran los responsables de la convección. Además se identificaron dentro de estos días cuando se formaron las estructuras coherentes.

El mes de junio de 2007 se caracterizó por ser atípico para Cuba (Ballester, 2007), ya que se presentaron situaciones meteorológicas diversas.

Durante los dos primeros días del mes gran parte de Cuba se mantuvo bajo la influencia de las bandas de nublados y lluvias asociadas con la tormenta tropical Barry, 


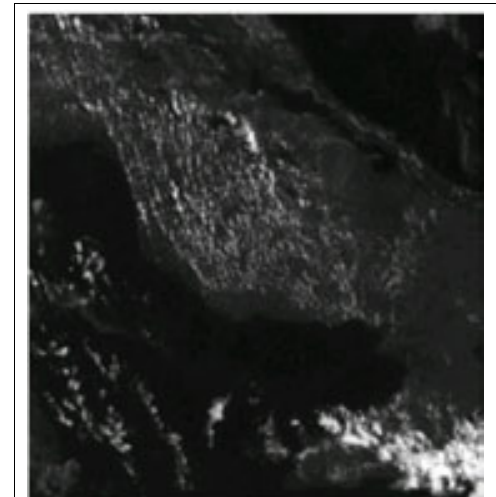

05.JUN.07 0945 h

a-1

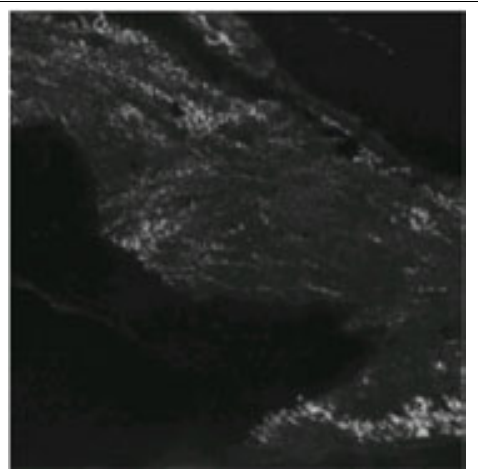

21.JUN.07 16.10 h

a-2

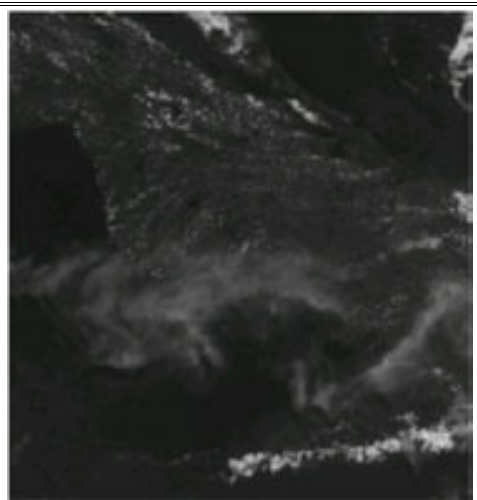

28.JUN.07 1145 h

a-3

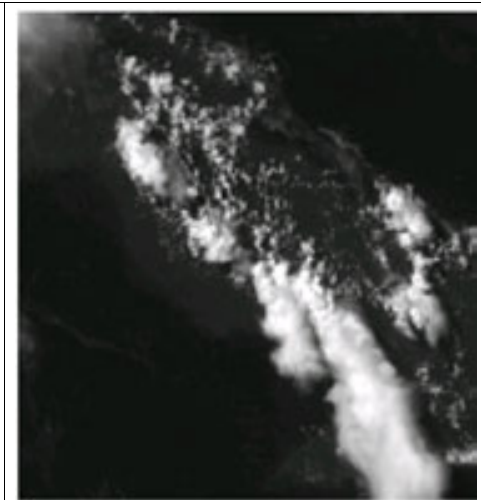

05.JUN.07 1432 h

b-1

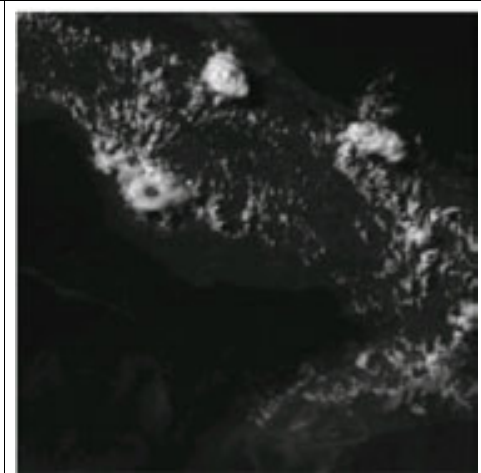

21.JUN.07 16.10 h

b-2

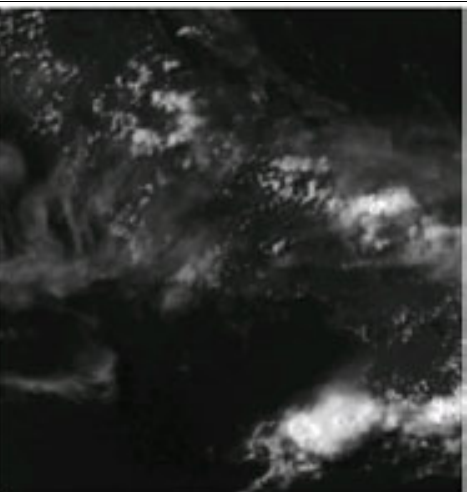

28.JUN.07 1445 h

b-3

Figura 1 - Imágenes de satélites de la banda visible del los días 5, 21 y 28 de junio, donde a-1), a-2) y a-3) muestran los estadíos tempranos de la convección en horas de la mañana con patrón nuboso asociado a Rollos Convectivos Horizontales; b-1), b-2) y b-3) muestran mayor desarrollo convectivo con la presencia de nubosidad asociada a Celdas de Rayleigh - Bénard abiertas, fundamntalmente en la tarde.

el día 3, una vaguada que se extendía desde una baja extra tropical remanente de Barry influyó sobre el centro del país. Los días 4, 5 y 6 las altas presiones subtropicales imperaron en superficie, mientras que un flujo húmedo en los niveles bajos en combinación con una difluencia en la alta troposfera incentivó los procesos convectivos. El día 7 se mantuvo la dorsal subtropical, debilitándose después. El día 8 una baja superior sobre la Florida favoreció la convección sobre Matanzas y las 
provincias centrales. Esta baja superior se trasladó hacia el suroeste influyendo sobre Cuba los días 9 y 10. Este último día la presión superficial estaba baja y el gradiente bárico era muy débil. El paso de una onda tropical por los mares al sur de Cuba los días 11 y 12 en conjunción con una vaguada superior incentivaron los procesos convectivos.

Desde el día 13 hasta el 15 persistieron las condiciones favorables para la ocurrencia de lluvias debido a la presencia de una vaguada en los niveles medios y a las bajas presiones en superficie. Esas condiciones continuaron el día 16 producto de una hondonada sobre el sudeste del Golfo de México en conjunción con la vaguada de niveles medios. El día 17 comenzó a restablecerse la influencia anticiclónica, la cual se mantuvo hasta el 19. Entre los días 20 y 23 se localizaba un área de bajas presiones sobre la Florida y mares al norte de las Bahamas Septentrionales, con un gradiente bárico débil sobre Cuba, por lo que la convección estuvo condicionada fundamentalmente por el fuerte calentamiento diurno. La presión atmosférica superficial se incrementaba entre los días 24 y 26, mientras que en la troposfera superior una vaguada se trasladaba desde el oriente hacia el centro de Cuba. El día 27, los procesos convectivos fueron favorecidos por una difluencia asociada con una baja superior localizada en el sudeste del Golfo de México en conjunción con una onda tropical, que transitaba sobre la mitad oriental de Cuba. Al siguiente día, la baja superior se encontraba retirada hacia la Bahía de Campeche y la onda tropical se trasladaba sobre la mitad occidental. Durante los días 29 y 30 hubo una mayor influencia anticiclónica, quedando el régimen de lluvia determinado por el calentamiento diurno y la convergencia de las brisas.

A partir de lo antes mencionado se encontró que los días del 4 al 6, el 9 , del 17 al 21 y del 27 al 30 de junio, se presentaron las condiciones propicias para el desarrollo de la convección local, y además en las imágenes de satélite se observó que todos estos días hubo HCR al final de la mañana y principio de las tarde y luego con el desarrollo de la convección se formaron CRB abiertas (Figura 1).

Seguidamente se muestra el comportamiento de la velocidad vertical y de los números adimensionales calculados para este trabajo, en el mes de junio de 2007.

\subsection{Velocidad vertical}

La velocidad vertical se tomó en un primer momento como criterio para el inicio de la convección, cuando sus valores comenzaran a ser mayores que cero en horas de la mañana. Como se puede apreciar en la Figura 2, el gráfico de los datos tomados resultaba representativo de la hora de comienzo y la duración de la acción de las fuerzas de la flotabilidad, lo cual no era suficiente para asegurar que comenzara la convección, ya que es posible que las parcelas de aire que se eleva dando inicio a la convección no se encuentren en el nivel de la vertical donde se calculó la velocidad vertical, por ello en este trabajo se toma el criterio de $\mathrm{w}>0$ como forma de estimación del inicio de la convección en el caso donde la misma comience en la parte de la superficie donde se encuentre ubicada la torre de gradiente. La observación de la altura efectiva de la base de la convección podría ayudar a determinar el origen del ascenso con ayuda de la estimación del nivel de condensación por levantamiento. En ausencia de estas estimaciones es difícil afirmar que el valor de w calculada a partir de la mediciones realizadas en la torre sea representativo del inicio de la convección, es por ello que en este trabajo entonces se toma como condición necesaria pero no suficiente para que se inicie el ascenso por convección. En la Figura 3 se muestran dos ejemplos ( 5 y 6 de junio de 2007) donde se ve el comportamiento de la velocidad vertical y se compara con la observaciones de satélite donde se

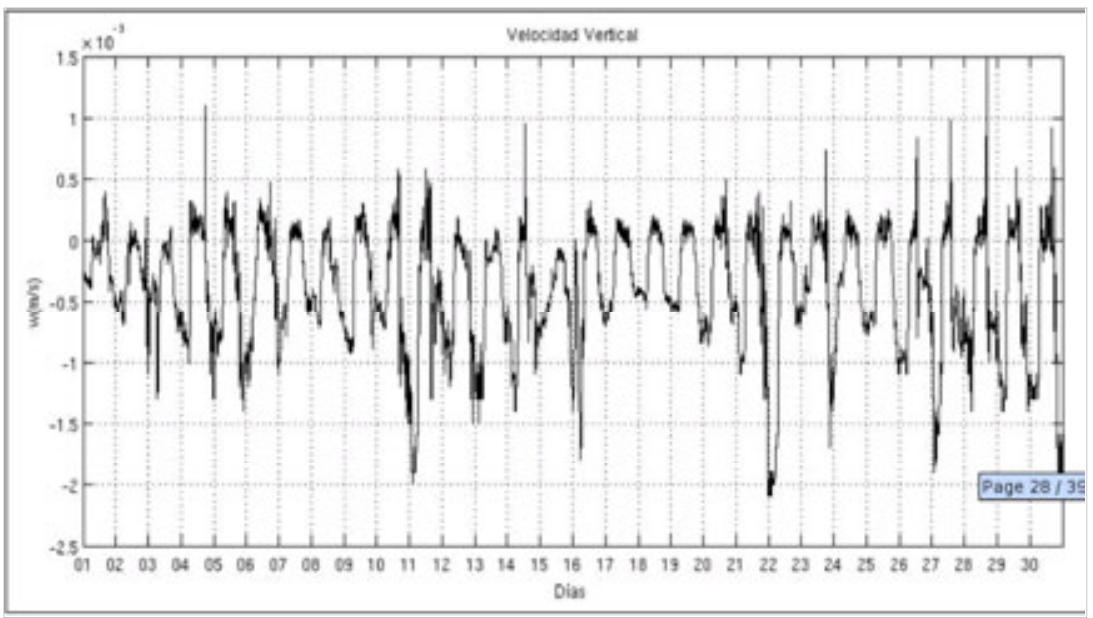

Figura 2 - Comportamiento de la velocidad vertical por días, calculada con la temperatura cada 10 minutos, durante el mes de junio 2007. 


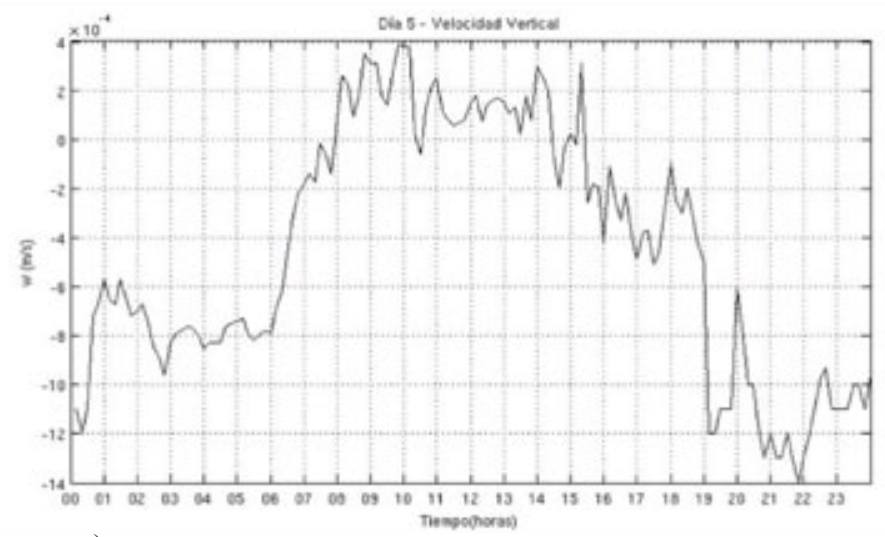

a)

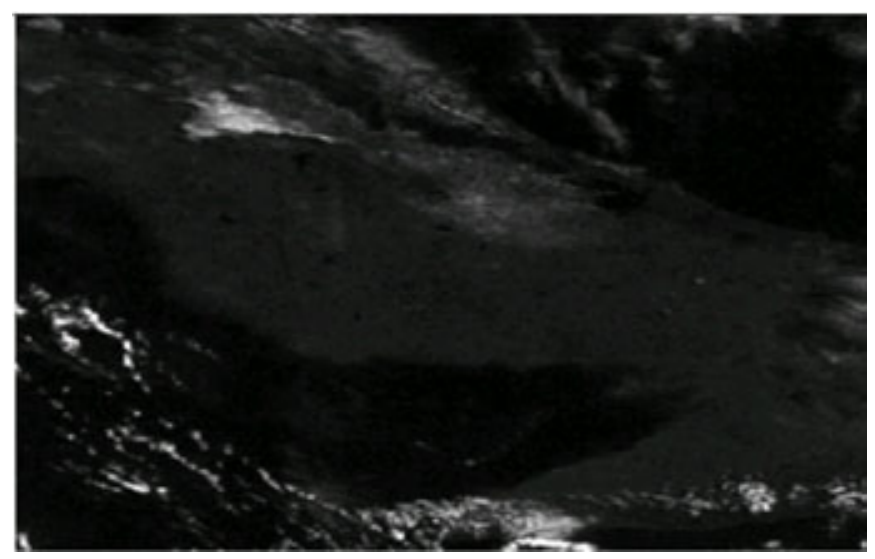

b) 05. JUN. $070801 \mathrm{~h}$

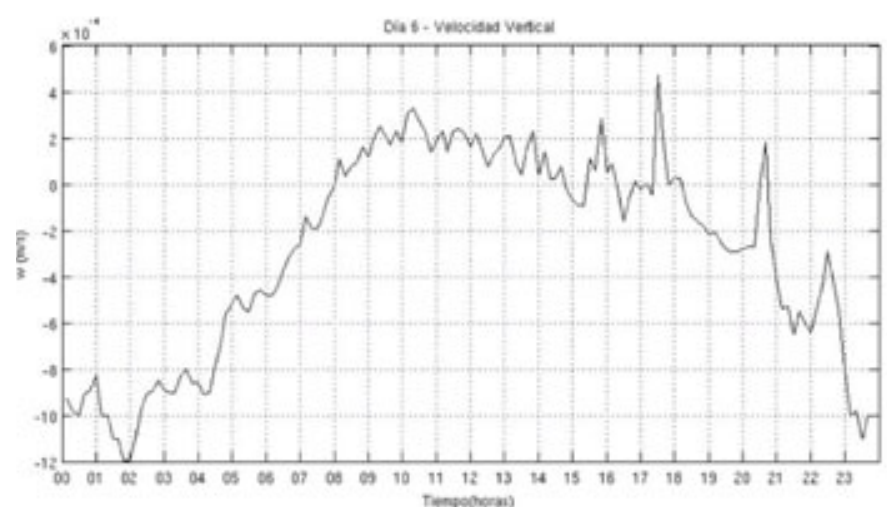

c)

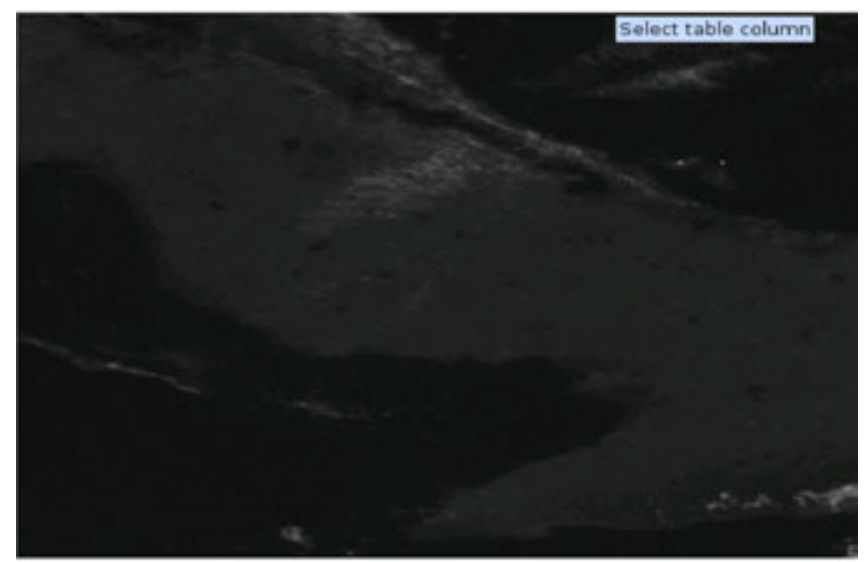

d) 06. JUN. $071001 \mathrm{~h}$

Figura 3 - Comportamiento de la velocidad vertical de los días 5 y 6 de junio de 2007, (a) y (c) respectivamente. Imágenes de satélite de la banda visible de un kilometro de resolusión de los días 5 y 6 de junio de 2007, (b) y (d) respectivamente.

puede apreciar que $\mathrm{w}$ se hace positiva en ambos caso a partir de las $0800 \mathrm{~h}$ y se mantiene con valores por encima de cero la mayor parte del día hasta las $1430 \mathrm{~h}$ aproximadamente que se hace negativa y continúa fluctuando con valores positivos y negativos. En el caso del día 5 de observó un valor negativo $\mathrm{w}$ a las $1030 \mathrm{~h}$.

Las imágenes de satélite por su parte muestran las escasez de nubosidad a las horas que $\mathrm{w}$ alcanza valores por encima de cero sólo se observan escasas nubes altas que no están relacionadas con las convección local, en el caso del día 6 a las 1000 h todavía no se observaba la nubosidad producto de la convección, lo cual puede estar relacionado con lo explicado anteriormente y además con el hecho de que debe existir un desfasaje en el tiempo desde que comienza la convección y cuando se forma la nubosidad.

\subsection{Número de Prandtl}

En relación a los valores de $\operatorname{Pr}$ para el aire, en la Tabla 1 se pueden apreciar los resultados de diferentes autores planteados por Carnesoltas et al. (2009), que se comparan con los obtenidos en este trabajo. Aunque se plantea que tanto los coeficientes que lo conforman como el propio número adimensional son propiedades sustantivas del fluido tales como lo son sus contrapartes moleculares, en realidad son características secundarias del campo del flujo (Kaimal y Finnigan, 1994), y ellas, como su relación $\operatorname{Pr}$ responden a todos los factores que influyen en el flujo y a los gradientes de momentum y de temperatura. De la misma forma, estos autores también plantean que "no debemos esperar estricta correspondencia para estas fórmulas esencialmente unidimensionales en condiciones advectivas, aunque ellas puedan indicar los cambios esperados".

Como puede apreciarse, el valor general del número de $\operatorname{Pr}$ de 0,73 obtenido a partir de la Ecuación 3 por los autores de la presente investigación, resulta totalmente aceptable, en especial con los resultados de Nahle (2006) para el aire; Byron et al. (1960) para el aire a 273,2 K; y el de V. Isachenko et al. (1969) para los gases diatómicos, y ligeramente superior a los que plantean Montgomery (1940) y Sutton (1953) para el aire; Brown (1972) 
Tabla 1 - Valores del número de Prandtl obtenidos por diferentes autores.

\begin{tabular}{|l|c|c|c|}
\hline \multicolumn{1}{|c|}{ Autor (es) } & Año & Sustancia & Pr \\
\hline Montgomery & 1947 & Aire & 0,71 \\
\hline O. G. Sutton & 1953 & Aire & $\sim 0,7$ \\
\hline R. Byron et al. & 1960 & Aire (273,2 K) & $0,73-0,74$ \\
\hline V. Isachenko et al. & 1969 & Gases monoatómicos & 0,67 \\
\hline & & Gases diatómicos & 0,72 \\
\hline R. A. Brown & 1972 & Aire (capa Ekman) & 0,7 \\
\hline J. Kaimal y J. Finnigan & 1994 & Aire (cond. neutrales) & 1,0 \\
\hline & & Aire (capa superficial) & 0,95 \\
\hline Emanuel & & Aire & 0,7 \\
\hline R. Fernández & 1994 & Aire & 0,71 \\
\hline Convección (www) & 2001 & Gases monoatómicos & 0,66 \\
\hline A. Ramos (www) & 2003 & Gases & $\sim 1,0$ \\
\hline Flujos térmicos (www) & 2004 & Gases & 0,5 \\
\hline N. Nahle & 2004 & Gases & $\sim 1$ \\
\hline N. Puintana., M. Sierra y & 2009 & Aire (10 - 100 m) & 0,743 \\
\hline
\end{tabular}

para el aire en la capa de Ekman; y Kaimal y Finnigan (1994) para el aire. Aunque los autores mencionados aclaran que los valores pueden variar en las condiciones reales para cada fluido.

El primer resultado que se obtuvo fue el valor del número de Prandtl para determinar las características del fluido con que se estaba trabajando, el cual osciló entre 0.71 y 0.74 durante el mes seleccionado, con una moda de 0.73 .

\subsection{Número de Rayleigh}

Por otro lado, si el cálculo del valor crítico del número de Rayleigh a partir del cual comienza la convección, se realizara con los valores de los coeficientes de viscosidad y de difusividad térmica moleculares, se obtendrán valores en el orden de $10^{12}$ y $10^{13}$, lo que significa que las fuerzas viscosas son despreciables dado el espesor de la capa tomada, o sea los valores obtenidos no son representativos de la convección en el espesor tomado. Luego, para el objetivo propuesto, fue necesario utilizar los valores de los coeficientes de difusividad térmica y viscosidad dinámica correspondientes a los flujos turbulentos, de manera que reflejaran la relación de las fuerzas que están actuando: la flotabilidad, la viscosidad y la difusión térmica. De esta forma los valores obtenidos siempre estuvieron en el orden de $10^{3}$ y $10^{5}$, que resultaban representativos de las características del flujo en la capa donde se realizaron las mediciones (R. Hernández, 2008, comunicación personal).

La Figura 4 muestra el esquema que representa el tipo de convección que deberá existir en dependencia del valor del número de Rayleigh planteado por Veltishchev (1990). En la figura puede apreciarse que cuando el número de $R a$ es mayor que el número crítico, y está en el orden de $10^{3}$, habrá

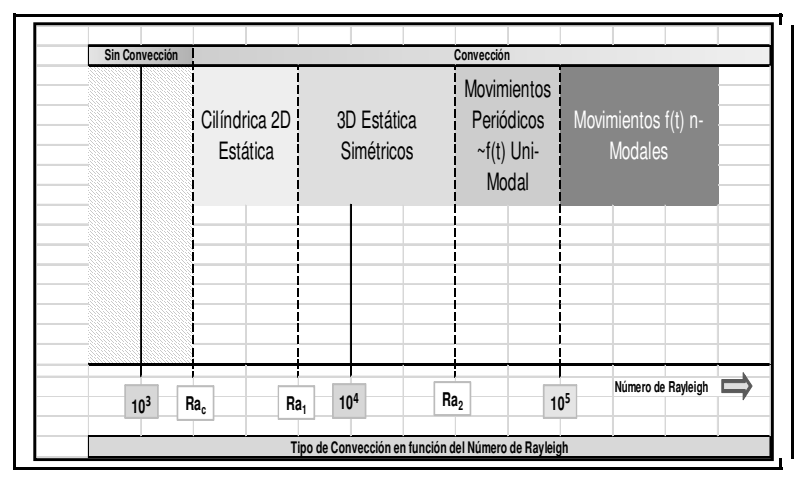

Figura 4 - Esquema representativo del tipo de convección a parir del número de Rayleigh, Veltishchev, N. F. (1990). 
Tabla 2 - Valores del número de Rayleigh para cada uno de los periodos escogidos.

\begin{tabular}{|c|c|c|c|c|}
\hline Periodo & & \begin{tabular}{|l|} 
Mínimo \\
Absoluto \\
\end{tabular} & $\begin{array}{l}\text { Máximo } \\
\text { Absoluto } \\
\end{array}$ & Mínimo $(w>0)$ \\
\hline $01-08$ & $\begin{array}{l}\text { VALOR } \\
\text { DIA } \\
\text { HORA }\end{array}$ & $\begin{array}{l}-3.98 \times 10^{5} \\
5 \\
2140 \mathrm{~h}\end{array}$ & $\begin{array}{l}4.96 \times 10^{5} \\
4 \\
1750 \mathrm{~h}\end{array}$ & $\begin{array}{l}1.32 \times 10^{3} \\
3 \\
1810 \mathrm{~h}\end{array}$ \\
\hline $09-16$ & $\begin{array}{l}\text { VALOR } \\
\text { DIA } \\
\text { HORA }\end{array}$ & $\begin{array}{l}-6.25 \times 10^{5} \\
11 \\
0230 \mathrm{~h} \\
\end{array}$ & $\begin{array}{l}4.89 \times 10^{5} \\
14 \\
1240 \mathrm{~h}\end{array}$ & $\begin{array}{l}1.35 \times 10^{3} \\
16 \\
1900 \mathrm{~h}\end{array}$ \\
\hline & VALOR & $-6.75 \times 10^{5}$ & $4.06 \times 10^{5}$ & $1.37 \times 10^{3}$ \\
\hline $17-24$ & DIA & 22 & 23 & 20 \\
\hline & HORA & $0110 \mathrm{~h}$ & $1830 \mathrm{~h}$ & $1820 \mathrm{~h}$ \\
\hline $25-30$ & $\begin{array}{l}\text { VALOR } \\
\text { DIA } \\
\text { HORA }\end{array}$ & $\begin{array}{l}-6.44 \times 10^{5} \\
30 \\
2110 \mathrm{~h}\end{array}$ & $\begin{array}{l}7.31 \times 10^{5} \\
28 \\
1610 \mathrm{~h}\end{array}$ & $\begin{array}{l}1.41 \times 10^{3} \\
25 \\
0640 \mathrm{~h}\end{array}$ \\
\hline MES & $\begin{array}{l}\text { VALOR } \\
\text { DIA } \\
\text { HORA }\end{array}$ & $\begin{array}{l}-6.75 \times 10^{5} \\
22 \\
0110 \mathrm{~h}\end{array}$ & $\begin{array}{l}7.31 \times 10^{5} \\
28 \\
1610 \mathrm{~h}\end{array}$ & $\begin{array}{l}1.32 \times 10^{3} \\
3 \\
1810 \mathrm{~h}\end{array}$ \\
\hline
\end{tabular}

convección y será del tipo cilíndrica 2D estática, en el orden de $10^{4}$ será $3 \mathrm{D}$ y con movimientos unimodales y en el orden de $10^{5}$ tendrá movimientos n-modales. En la investigación los valores obtenidos del número de $R a$ estuvieron en el orden de $10^{3}$ y $10^{5}$, como se planteó anteriormente, por lo que el esquema es representativo del tipo de convección que puede ocurrir bajo las condiciones de Cuba.

En la Tabla 2 se muestran los valores máximos y mínimos del número de Rayleigh del mes de junio del 2007, el cual se dividió en cuatro periodos para facilitar el análisis de la siguiente manera (Primer periodo, del 1 al 8 de junio; Segundo periodo del 9 al 16 de junio; Tercer periodo del 17 al 24 de junio; Cuarto periodo del 25 al 30 de junio). El valor del número de $R a$ máximo absoluto en el mes fue $R a=$ $7.31 \times 10^{5}$ el 28 de junio a las $1610 \mathrm{~h}$ y el mínimo absoluto fue de $R a=-6.75 \times 10^{5}$ el 22 de junio a las $0110 \mathrm{~h}$, por su parte el número mínimo encontrado cuando la velocidad vertical era positiva fue de $R a=1.32 \times 10^{3}$ el 3 de junio a las $1810 \mathrm{~h}$, el cual se puede plantear como el número de $R a$ crítico en la muestra tomada.

Como se puede observar en el primer periodo (del 1-8 de junio), el valor del mínimo absoluto fue el mayor de todos los valores encontrados en el mes mientras que el mínimo con la condición de velocidad vertical positiva fue el valor más pequeño de toda la muestra, lo cual evidencia que las condiciones térmicas (la fuerza de flotabilidad) estaban influyendo fuertemente en el flujo, por lo que la convección comenzó más rápido y con un número de Ra más pequeño.

\subsection{Número de Richardson}

En el inicio de la convección y la posterior formación de las celdas y/o los rollos intervienen, tanto las fuerzas de flotabilidad como las fuerzas inerciales, por lo que se calculó el número de Richardson con el objetivo de observar el comportamiento de estas dos fuerzas durante la ocurrencia de los proceso convectivos en los días escogidos para esta investigación. Inicialmente, en el cálculo del número de $R i$ se tomó la velocidad del viento $V$ como el promedio de velocidades de los cuatro niveles que mide la torre (Expresión 6). Sin embargo, los valores así obtenidos no resultaban del todo representativos de los procesos que ocurrieron en el periodo tomado, ya que amortiguaba los valores del $R i$, dando como resultado que no se evidenciará el inicio de la convección, como se muestra en la Figura 5. Los valores del número de $R i$ calculados tomando la velocidad del viento $V$ con los valores medidos a $10 \mathrm{~m}$ de altura, mostraron que durante las horas de sol fueron en su mayoría positivos, mientras que durante la noche ocurre lo contrario.

Al tratar de relacionar el resultado del número $R i$ con los valores de la velocidad del viento, para encontrar un valor crítico a partir del cual se pueda estimar el inicio de la convección, se encontró, como era de esperar, que esta relación no era lineal. No siempre se observará coincidencia entre la existencia de valores positivos de la flotabilidad y el inicio de la convección, dado por el número de $R i$, lo que significa que en los casos donde ocurre esto, las fuerzas inerciales (acción del viento) es más significativa que el efecto de la flotabilidad provocado por el gradiente térmico; por tanto las fuerzas inerciales a partir de determinados valores de la velocidad del viento (que no siempre serán los mismos) inhibirán el comienzo de la convección aún cuando la componente térmica del proceso ya esté presente.

El análisis de los valores obtenidos del número $R i$ de cada día permitió dividir el comportamiento de la convección en tres grupos:

Grupo 1: Diferencias de temperaturas pequeñas con altas velocidades del viento, lo que significó un dominio de las fuerzas inerciales sobre las de flotabilidad, en este caso se pudo plantear que no había convección, o que si se producía sería muy débil y de poca duración.

Grupo 2: Diferencias de temperaturas altas con altas velocidades del viento, o diferencias de temperaturas bajas con bajas velocidades del viento. En ambos casos se puede decir que existirá un equilibrio (relativo) entre las fuerzas de flotabilidad y las fuerzas inerciales. Esto no significa que estas fuerzas tengan iguales valores, sino que están en el mismo orden de magnitud. En este caso se pudo plantear que la convección sería moderada, con algunos "picos" en momentos donde el viento fluctuara de manera negativa que serán de poca duración. Las causas de ambas situaciones pueden ser, en primer lugar, porque aún cuando las condiciones térmicas fueran favorables, la advección horizontal de calor producto de la alta velocidad del viento era tan fuerte, que el calentamiento no pudo formar una corriente ascendente lo suficientemente vigorosa capaz de comenzar o sostener la corriente convectiva; y en el segundo caso, porque 
aún cuando la velocidad del viento fue débil, favorable para que ocurriera la convección desde el punto de vista térmico, la fuente de energía, o sea el combustible térmico, no fue suficiente para que la convección se fortaleciera. Por lo tanto, en ambas situaciones la convección debería ser moderada.

Grupo 3: Diferencia de temperaturas grandes con pequeñas velocidades del viento, las fuerzas de flotabilidad superan las fuerzas inerciales, o juegan un papel más importante. Esta fue la condición idónea para que se desarrollara y sostuviera una poderosa corriente convectiva, porque estaba presente un fuerte gradiente térmico que iniciaba la convección, mientras que el viento débil no imposibilitaba el ascenso de masa ni de energía en forma de calor en la columna vertical. Por tanto en este grupo se pudo plantear que habría convección fuerte y de larga duración.

Luego de observar el comportamiento tanto del número de $R a$ como del número de $R i$, se encontró que la conjugación de los mismos proporcionaba una idea acertada del comportamiento de la convección desde el punto de vista del tipo e intensidad de la misma; ya que a partir del número de $R a$ pudiera determinarse cuando comienza y además que tipo de estructura tendría en dependencia del rango de valores en el cual se encontraba el mismo, mientras que con el número de Richardson se pudo observar cuán importante fue la acción de las fuerzas inerciales en el proceso de la convección y la intensidad de la misma.

\subsection{Ejemplo representativo}

Luego de ver por separado el comportamiento de cada uno de los parámetros calculados, se tomó un día del mes donde se analizaron en conjunto y se compararon con lo que se obtuvo del análisis espectral de la vorticidad con la transformada continua de Wavelet.Tomando como ejemplo el 4 de junio de 2007, se pudo observar en el mapa de superficie de las 1200 UTC, que Cuba se encontraba bajo la fuerte influencia de las altas presiones oceánicas con centro sobre el Atlántico Norte, con vientos variables débiles y con predominio de brisas en la tarde. Este sistema estuvo representado en los niveles bajos y medios de la atmósfera por una faja de altos geopotenciales, con centro en niveles bajos al Norte de la Española, a partir de los $700 \mathrm{hPa}$ el eje de la misma comienza a inclinarse con la altura al SW apareciendo un centro en los mares al sur de la región centro-oriental de Cuba, generando un flujo del SE al $\mathrm{S}$ en niveles bajos (850 y $925 \mathrm{hPa}$ ), del S al SW en niveles medios $(500$ y $700 \mathrm{hPa})$ y del NW en los altos $(200$ y $300 \mathrm{hPa})$ (Figura 6a-6d).

En cuanto a la humedad relativa en el nivel de $300 \mathrm{hPa}$ se encontraba un centro de mínimas con valores menores a $5 \%$ sobre el Golfo de México, y sobre Cuba se extendía una zona de poca humedad con valores de $20 \%$ y al norte de La Española a $\operatorname{los} 22^{\circ} \mathrm{N}$ y $73^{\circ} \mathrm{W}$ se encontraba otro centro de mínima con valores menores de $10 \%$, pero en el nivel de $500 \mathrm{hPa}$ un fuerte gradiente de humedad abarcaba casi todo el territorio cubano con un valor promedio de $40 \%$, un centro de máxima humedad se encontraba sobre el Mar Caribe en los $17^{\circ} \mathrm{N}$ y $80^{\circ} \mathrm{W}$ al sur de la región central de Cuba y además de un centro de mínima con valores menores de $5 \%$ en $\operatorname{los} 25^{\circ} \mathrm{N}$ y $85^{\circ} \mathrm{W}$ se extendía sobre el Golfo de México hasta el estrecho de la Florida y la parte occidental de Cuba. En el caso del nivel de $850 \mathrm{hPa}$ un centro de mínima menor de $40 \%$ se encontraba sobre el Golfo de México y un centro de máxima humedad mayor de $75 \%$ se

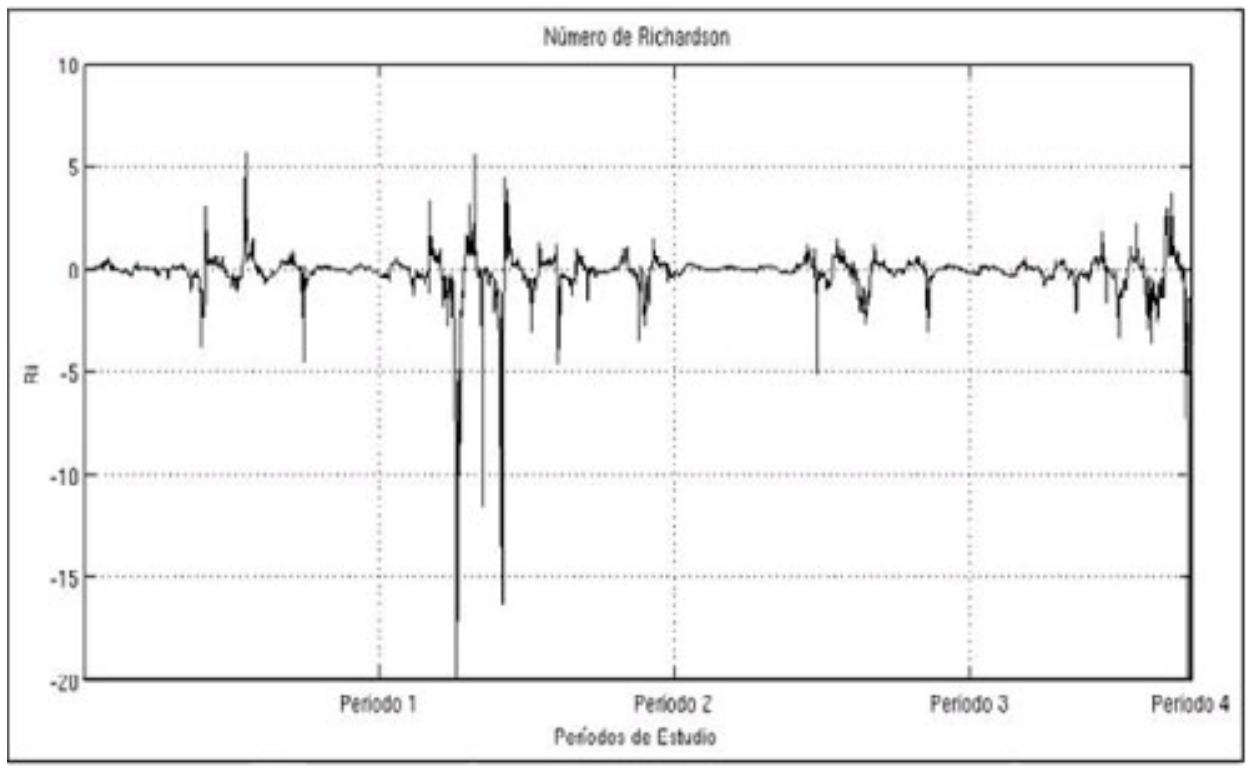

Figura 5 - Valores del número de Richardson durante todo el mes de junio, calculados con la velocidad media del fluido. 


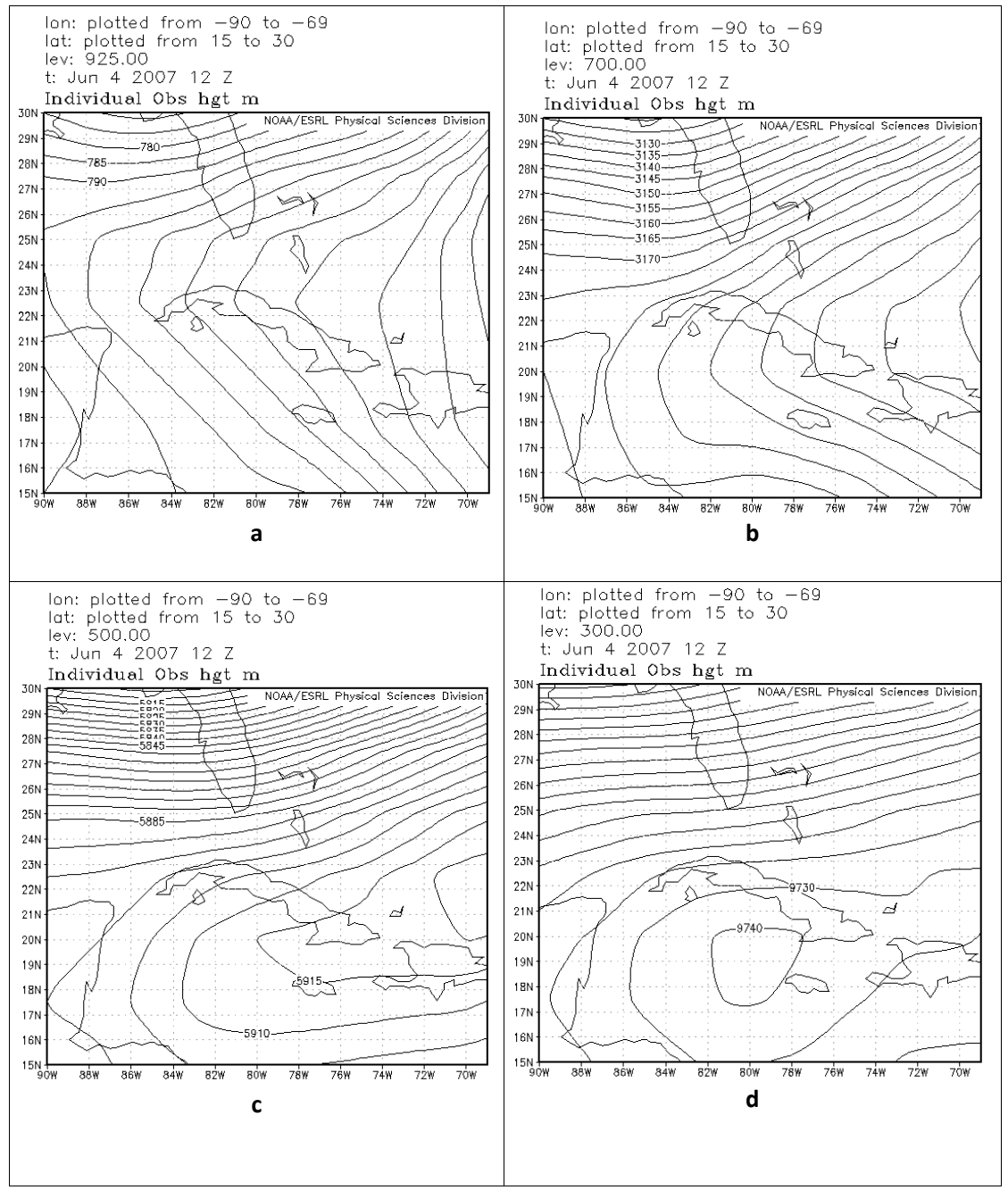

Figura 6 - Geopotencial del día 4 de junio de 2007. A las 0700 h (1200) UTC: a) 925 hPa; b) 700 hPa, c) 500 hPa; c) 300 hPa.

encontraba sobre la parte centro-oriental de Cuba. Ya en el nivel de $925 \mathrm{hPa}$ Cuba se hallaba bajo la influencia de un centro de mínima menor de $62 \%$ que se encontraba sobre al norte de la región oriental del país a los $23^{\circ} \mathrm{N}$ y $73^{\circ} \mathrm{W}$ y se extendía sobre toda esta región, además otro centro pero de máxima humedad con valores mayores de $77 \%$ se encontraba sobre la zona occidental. Sobre la región de estudio los valores oscilaron entre 70 y $75 \%$ en los niveles bajos (ver Figura 7a-7d).

En cuanto a las temperaturas (Figura 8a-8d) se evidencia el gradual descenso de la temperatura potencial con la altura, característica normal de esta variable, se observó un fuerte gradiente con un valor promedio de $300 \mathrm{~K}$ en el nivel de $1000 \mathrm{hPa}$ sobre Cuba, que se mantuvo en toda la vertical con valores promedios de $283 \mathrm{~K}$ en el nivel de $700 \mathrm{hPa}, 258 \mathrm{~K}$ en $500 \mathrm{hPa}$ y 219 en $300 \mathrm{hPa}$. Además se observaron centros de máxima en todos los niveles de geopotencial sobre los mares adyacentes a Cuba como por ejemplo en $700 \mathrm{hPa}$ con un valor de $284 \mathrm{~K}$ sobre el Mar Caribe en los $18^{\circ} \mathrm{N}$ y $83^{\circ} \mathrm{W}$, en $500 \mathrm{hPa}$ el centro tenía un valor de $268 \mathrm{~K}$ y se encontraba sobre el Estrecho de la Florida y en $200 \mathrm{hPa}$ la temperatura potencial del centro tenía un valor de $219 \mathrm{~K}$ y se ubicaba al sur de la provincias centrales de Cuba en el Mar Caribe en $\operatorname{los} 20^{\circ} \mathrm{N}$ y $80^{\circ} \mathrm{W}$.

A partir de lo analizado anteriormente se pudo corroborar que el 4 de junio del 2007 las altas presiones subtropicales imperaron en superficie, mientras que un flujo húmedo en los niveles bajos en combinación con una difluencia en la alta troposfera incentivó los procesos convectivos, con lluvias fuertes en algunas localidades de país, o sea existían las condiciones idóneas para la ocurrencia de procesos convectivos locales incentivados por el calentamiento diurno y la resultante inestabilidad de la atmósfera.

$\mathrm{Al}$ ver el comportamiento de la velocidad vertical en la Figura 9, se pudo observar que comienza a incrementarse a partir de las $0500 \mathrm{~h}$ hasta que a las $0530 \mathrm{~h}$ sobrepasa el valor de cero, ya luego de se mantuvo fluctuando durante todo el día 
pero siempre siendo positiva hasta las $1700 \mathrm{~h}$ que decreció de forma abrupta, luego de las $1800 \mathrm{~h}$ ya se mantenía fluctuando cerca del valor de cero hasta las $2000 \mathrm{~h}$ donde ya se mantuvo negativa y decreciendo con el tiempo. En el transcurso de la noche experimentó aumentos y descenso producto de las intermitencias de la turbulencia que se manifiestan en la capa fronteriza nocturna (Buenestado, 2003).

Por su parte el número de $R a$ manifestó un comportamiento similar al de la velocidad vertical sólo que desfasado unos minutos, corroborando la hipótesis de lo necesidad de que la velocidad vertical sea positiva para que luego el número de Rayleigh alcance su valor crítico y comience la convección. Este día presentó el valor del número de Rayleigh más elevado de todo el mes, como ya se mencionó anteriormente de $R a=4.96$ x $10^{5}$ a las $1725 \mathrm{~h}$, lo cual evidencia la existencia de condiciones idóneas para el inicio y posterior desarrollo de la convección, o sea fuerte influencia de las fuerzas inerciales sobre el fluido (Figura 10).
Durante las primeras horas del día se mantiene y fortalece la inversión observada desde la madrugada del día 3 , por lo que no hay convección, mostrando el valor más bajo del Ri <-50. Esta situación fue observada hasta las $0630 \mathrm{~h}$, cuando ya comienza a restablecerse la distribución normal de la temperatura con un aumento en superficie producto de la influencia de la radiación. Durante el periodo del día mencionado anteriormente las velocidades del viento no fueron grandes, con valores entre $2.6 \mathrm{~m} / \mathrm{s}$ como la mayor observada y tendiendo a disminuir hasta alcanzar el valor de $0.1 \mathrm{~m} / \mathrm{s}$. De forma general durante todo el día las velocidades fueron débiles con una velocidad media de $2.1 \mathrm{~m} / \mathrm{s}$; por esto y por un aumento fuerte de las temperaturas de $24.1^{\circ} \mathrm{C}$ hasta $32.8^{\circ} \mathrm{C}$ se observa un pico positivo de $R \mathrm{i}=12$, o sea, un predominio de las fuerzas de flotabilidad sobre las fuerzas inerciales que evidencia la existencia de la convección (Figura 11).

La Figura 12 muestra los gráficos obtenidos del analisis de la vorticidad a través de la transformada de wavelet. Los

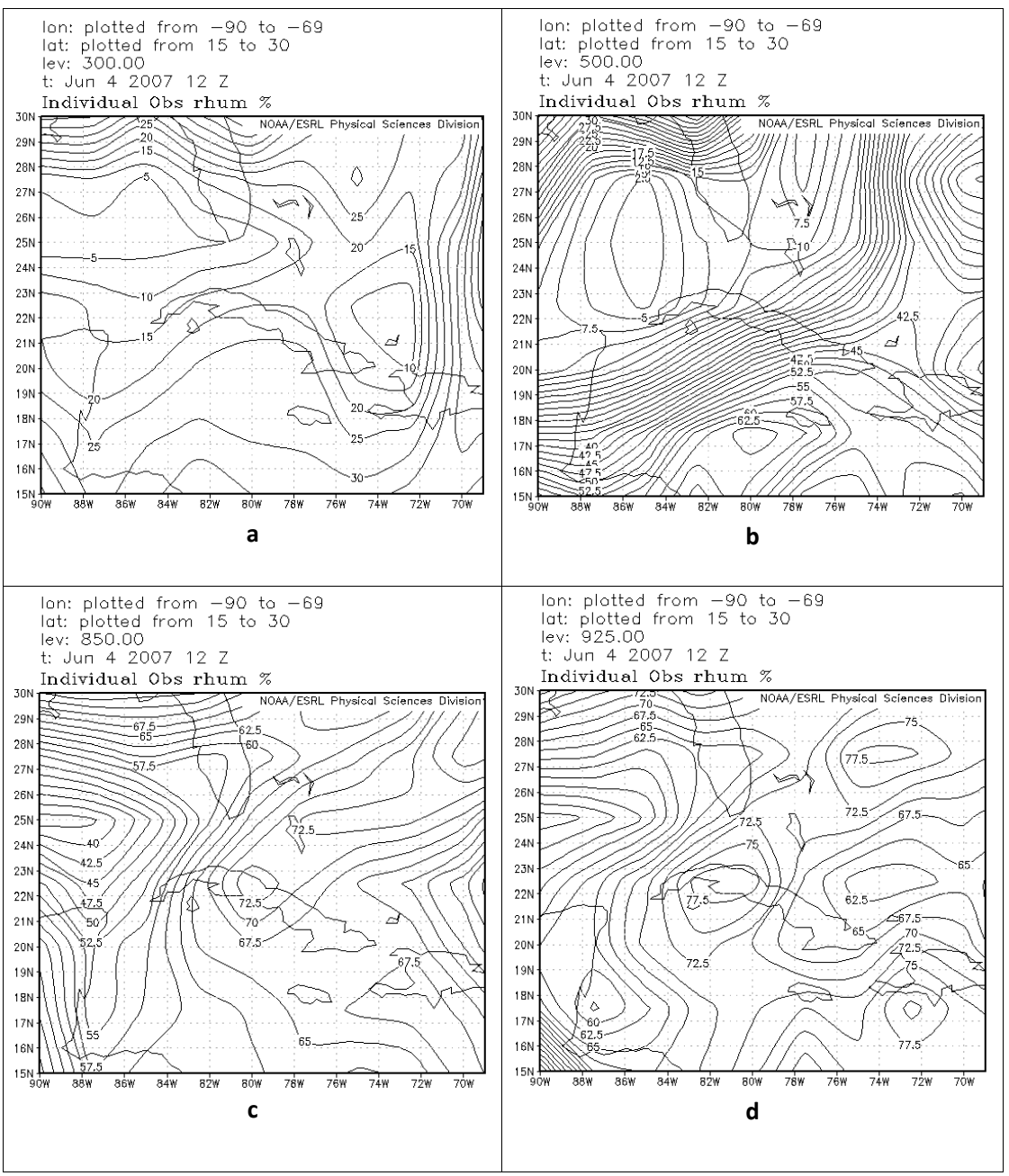

Figura 7 - Humedad Relativa, 4 de junio de 2007, 0700 h (1200) UTC: a) 300 hPa; b) 500hPa; c) 850 hPa; d) 925 hPa. 


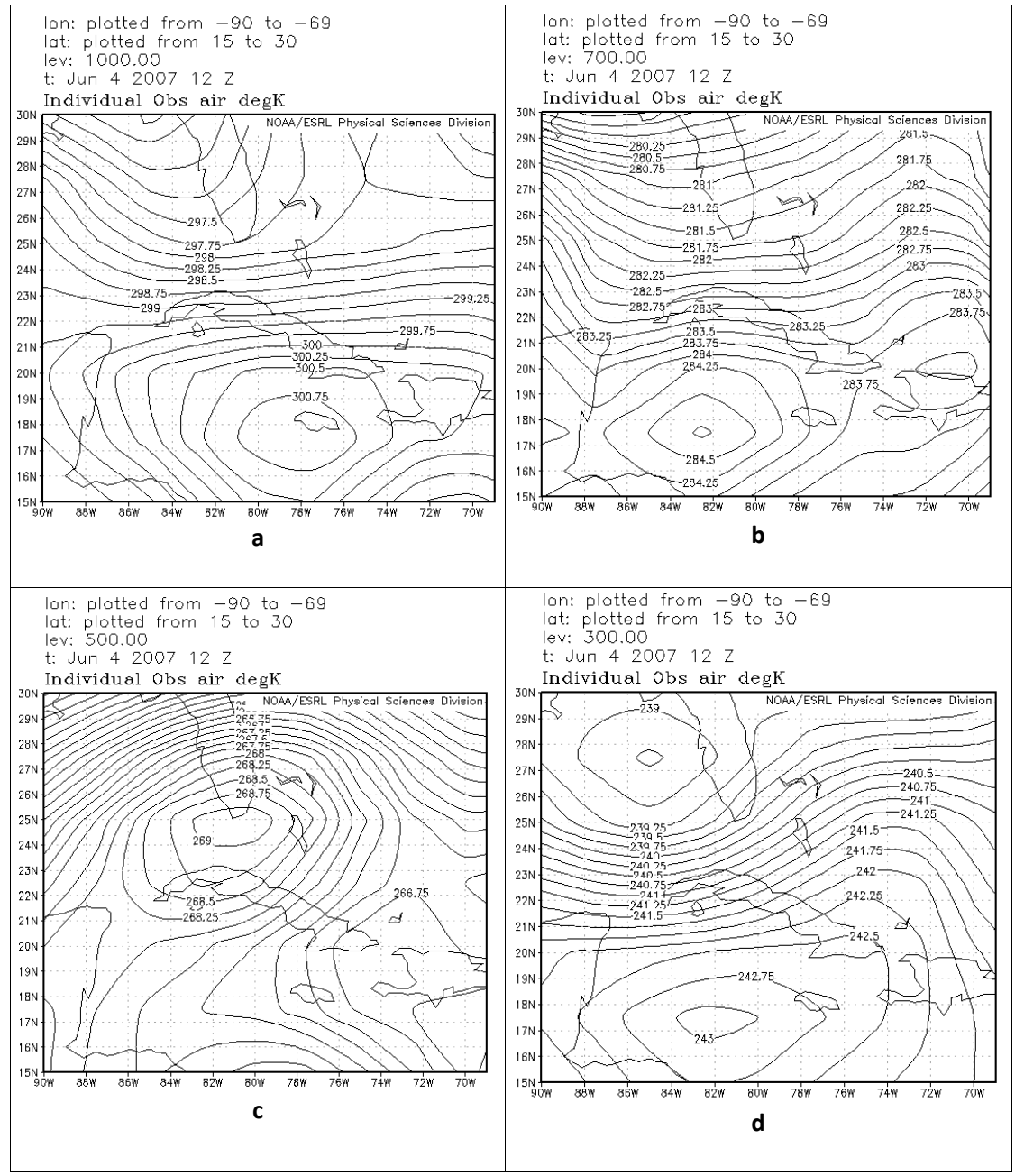

Figura 8 - Temperatura potencial, 4 de junio de 2007. A las 0700 h (1200) UTC: a) 1000 hPa; b) 700 hPa, c) 500 hPa; c) 300 hPa.

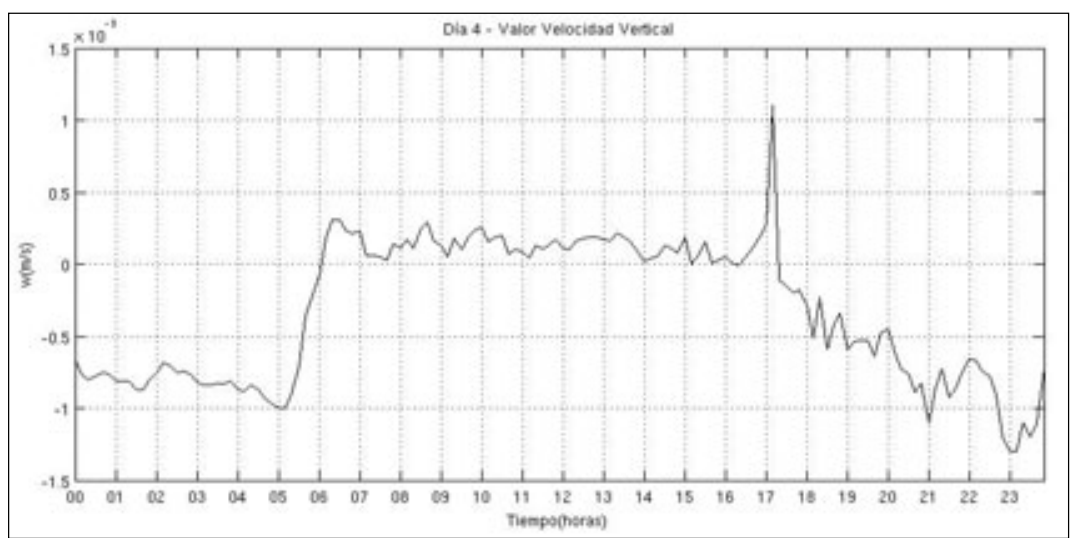

Figura 9 - Comportamiento de la velocidad vertical respecto al tiempo, del 4 de junio de 2007. 
mismos se obtuvieron con los datos de la velocidade del viento en sus componentes u y v, durante el día 4 de junio de 2007.

En ellos se muestran los máximos locales de la densidad de energía en los periodos de las $1300 \mathrm{~h}$ a las $1400 \mathrm{~h}$ y de las $1700 \mathrm{~h}$ a las $1800 \mathrm{~h}$, lo cual es consistente con la "intermitencia" de la concentracción de energía, cuando hay estructuras de este tipo presentes, propuesta por Farge(1988). El análisis de los coeficientes de la transformada de wavelet del campo de la vorticidad, muestra concentraciones desde el final de la maňana hasta final de la tarde para las escalas menores que 8 en niveles bajos, y de 12 hasta 20 en niveles más altos de la troposfera, lo que está asociado a la presencia de estructuras coherentes en desarrollo, que junto al elevado contenido de humedad disponible, dieron lugar a nubes que se fueron desarrollando hasta llegar a la etapa de convección profunda.
Puesto que el punto de cambio de valores negativos a positivos de los números de $R a$ y de $R i$ y de la velocidad vertical coinciden con el punto de cambio de mínima a máxima concentración de la vorticidad observado entre las 0600 y las $0700 \mathrm{~h}$ es posible decir que se evidencia el cambio en las condiciones atmosfericas en superficie a partir de la influencia de la radiación solar, el resto de los valores máximos de vorticidad se observaron en el periodo donde los valores de los números adimensionales calculados se comportaron positivos y con valores significativos.

Lo antes mencionado se corrobora con lo observado en las imágenes del satélite del día 4, donde se aprecia la formación de patrones nubosos representativos de la convección local correspondientes a los momento del día de máxima vorticidad observados en los niveles bajos; en este caso nubes fracto

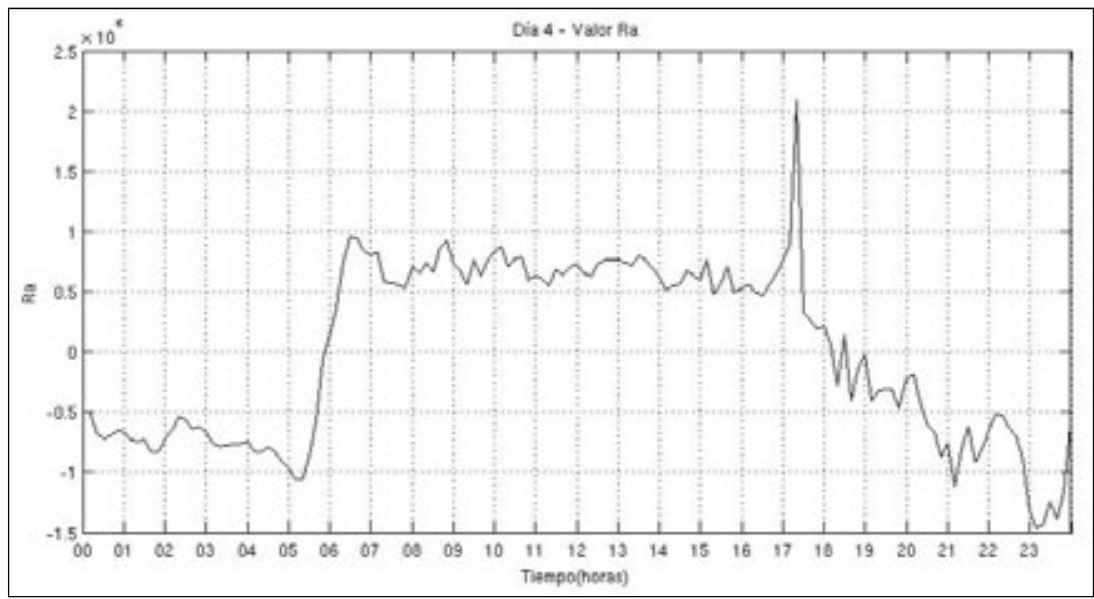

Figura 10 - Comportamiento del número de Ra respecto al tiempo, del 4 de junio de 2007.

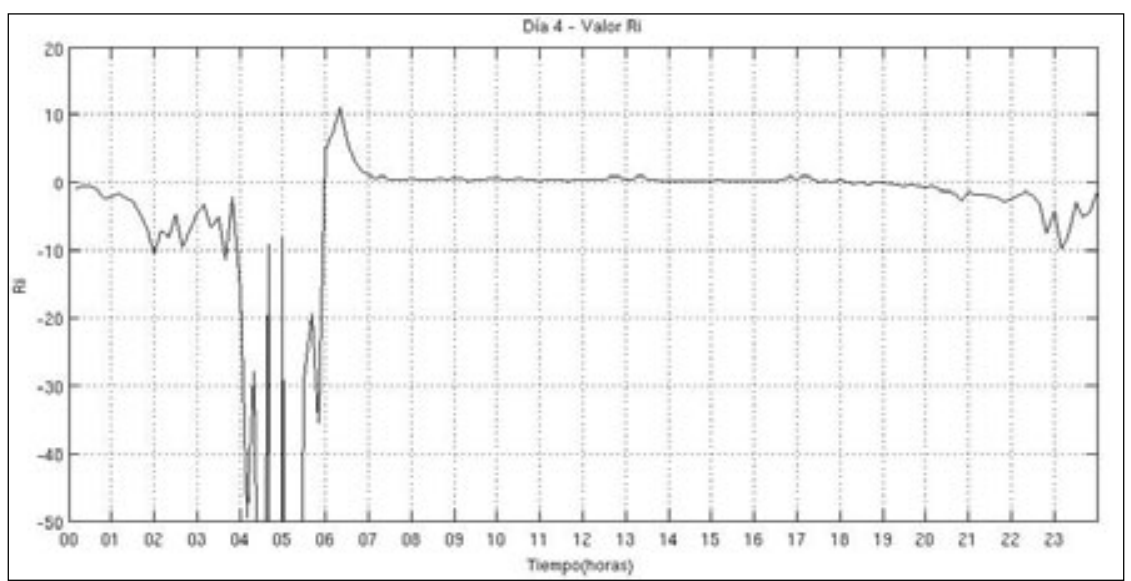

Figura 11 - Comportamiento del número de Ri respecto al tiempo, del 4 de junio del 2007, calculados con la velocidad del viento al nivel de 10 m. 

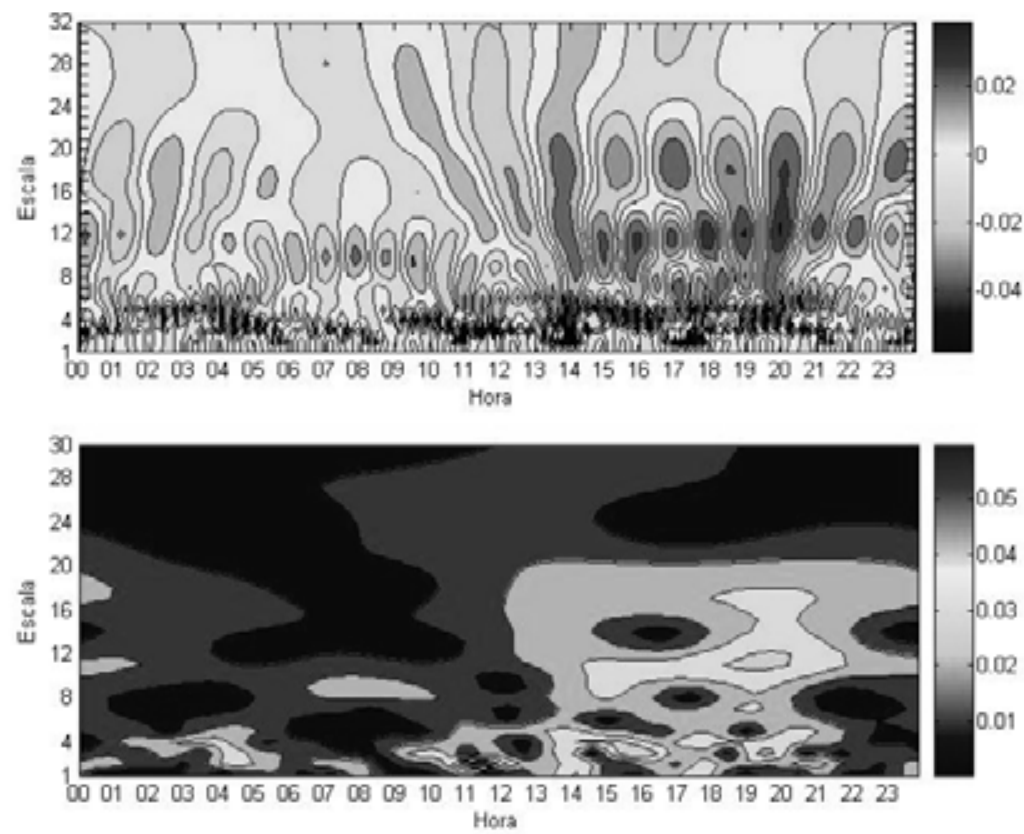

Figura 12 - Comportamiento de la vorticidad en la capa fronteriza atmosferica en los niveles de 10 y 100 metros, del día 4 de junio de 2007.

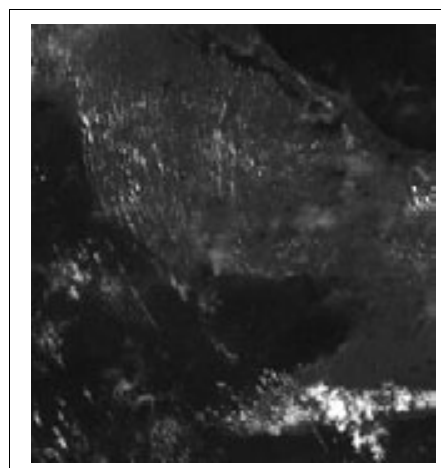

04.JUN.07 14.31 h

a

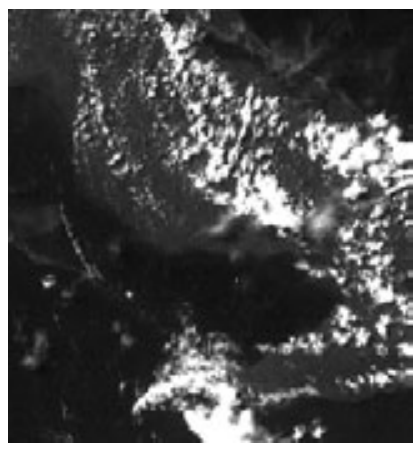

04.JUN.07 19.15 h

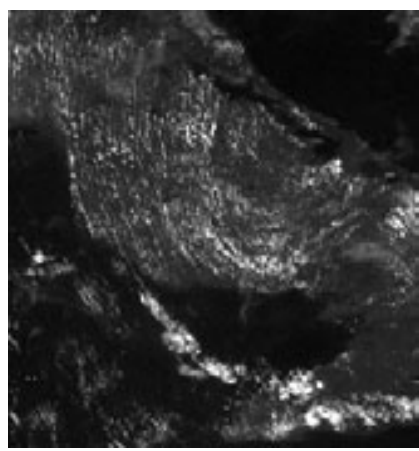

- 04.JUN.07 15.15 h

b

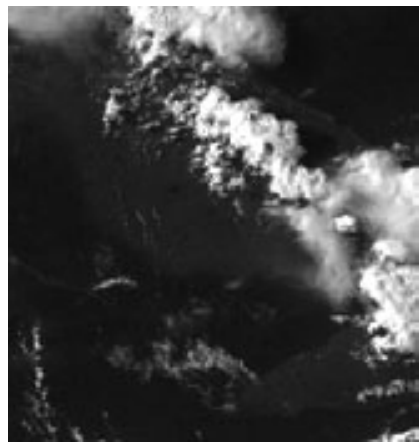

04.JUN.07 21.15 h

d

Figura 13 - Imágenes de satélite de la banda visible del 4 de junio de 2007; a) Imágen de las 14:13 h donde la convección era incipiente y comenzaba a organizarse la nubosidad en forma de HCR; b) Imágen de la 1015 h donde ya se definían la calles de nubes bien organizada; c) Imágen de las 1415 $\mathrm{h}$ donde ya la nubosidad se porganizaba en foema de celdas abiertas; d) Imágen de la 1615 h donde la nubosidad ya era profunda y se observaban lineas de cumulunimbos. 
cúmulos y cúmulos humilis, mediocris y congestus organizados en calles de nubes, patrón nuboso asociado a la formación de Rollos Conectivos Horizontales. Además se observaron nubes ya de mayor desarrollo vertical, cuando la convección se organizaba en forma de Celdas de Rayleigh - Bénard abiertas y más tarde se profundizaba dando lugar a precipitaciones en superficie (Figura 13a-13d).

\section{CONCLUSIONES}

Se puede plantear que la velocidad vertical positiva es la condición necesaria para el inicio de la convección, el número de Rayleigh puede tomarse como representativo del tipo de convección que se deberá formar y el número de Richardson de su intensidad.

El inicio de la convección ocurre cuando la velocidad vertical se hace positiva y un instante después el número de Rayleigh sobrepasa su valor crítico de $1.32 \times 10^{3}$.

Los Royos Convectivos Horizontales (en la muestra tomada) se forman fundamentalmente poco tiempo después que comienza la convección mientras que las Celdas de RayleighBénard abiertas, se forman mayormente cuando ya existe convección profunda.

Tanto el número de Rayleigh como el número de Richardson, fueron positivos todos los días en el horario diurno (entre las 06:30 h y las 20:00 h aproximadamente), mientras que lo opuesto ocurrió durante las noches, mostrando las diferencia existente entre la Capa Limite Convectiva y la nocturna.

El análisis de la vorticidad utilizando la transformada continua de Wavelet identificó correctamente la presencia de estructuras coherentes producto de la organización de la convección local.

\section{REFERENCIAS BIBLIOGRÁFICAS}

BALLESTER, M., Resumen mensual de la situación sinóptica (mayo-noviembre), Centro de Pronósticos del Instituto de Meteorología, 13 p, 2007. <www.insmet.cu>.

BROWN, R, A.,On the inflection point instability of a stratified Ekman boundary layer, Journal Atmospheric Science, 29:850 859, 1972.

BUENESTADO, P., Análisis y caracterización de la Capa Superficial Atmosférica, Tesis de Doctorado en Ciencias Físicas, Universidad de Barcelona. 154 p, 2003.

BUSINGER, J. A., Turbulent Transfer in the Atmospheric Surface Layer, in D. H. Haugen (ed.), Workshop on Micrometeorology, American Meteorol. Soc., Boston, MA, p.67-100, 1973.

BYRON, R., Fenómenos de Transporte. Un estudio sistemático de los fundamentos del transporte de materia, energía y cantidad de movimiento, La Habana: Editorial Pueblo Nuevo, tomado de la edición española de 1973, 823 p, 1960.

CARNESOLTAS, M., SIERRA, M., QUINTANA, N., Parámetros para detectar los sistemas locales de convección organizada en la capa fronteriza atmosférica sobre Camagüey, Informe de resultado, 63 p, 2009.

CHANDRASEKHAR, S., Hydrodynamic and Hydromagnetic Stability, Oxford University Press , 1961.

EMANUEL, K., Atmospheric Convection, Oxford University Press, 570 p, 1994.

FARGUE, M., RABREAU, G., Transformée en ondelettes pour déctecter et analyser les structures cohérentes dans les écoulements turbulent bidimensionnels, C. R. Acad. Sci. París, Sér. IIb. 307, 433p, 1988.

FERnANDEZ, R., Mecánica de los Fluidos. E. T. S. Ingenieros Industriales, Universidad de Málaga, 621 , 2001.

FOVELL, R. G., Convective Initiation ahead of the Sea-Breeze Front, Monthly Weather Review, v.133,p. 264-278, 2004 ISACHENCO, V., OSIPOVA, V., SUKOMEL, A., Heat Transfer, MIR Publisher, Moscow, 552 p, 1969.

KAIMAL, J. C., FINNIGAN, J. J., Atmospheric Boundary Layers Flow. Their Structure and Measurement, Oxford University Press, 281 p, 1994.

KOCH, S. E., RAY, C. A., Mesoanalysis of summertime convergence zones in central and eastern North Carolina, Weather and Forecasting, p. 56-77, 1997.

MAHRT, L., Stratified Atmospheric Boundary Layers and Breakdown of Models, J. Theor. Comput. Fluid. Dyn, p.263-280, 1998.

MAHRT, L., Stratified Atmospheric Boundary Layer, Boundary-Layer Meteorology, p.375-396, 1999.

MALHI, Y, S., The Significance of the Dual Solutions for Heat Fluxes Measured by the Temperature Fluctuation Method in Stable Conditions, Boundary-Layer Meteorology, 74, p.389-396, 1995.

MONTGOMERY, R, B.,Papers Phys. Oceanog. Meteorol. Mass. Inst. Technol. And Woods Hole Oceanog. Inst., 74, No. 4, 1940.

NAHLE, N., Transferencia de calor, Biology Gabinet, 2006. Disponible en $<$ http://www.biocab.org/Transferencia_Calor. html $>$. Acceso en enero del 2008.

OHYA, Y. D., NEFF, E., MERONEY, R. N., Turbulence Structure in a Stratified Boundary Layer under Stable Conditions, Boundary-Layer Meteorology, p.139-161, 1997.

PURDOM, J. F. W., Subjective interpretations of geostationary satellite data for nowcasting, Nowcasting. K. A. Browning (ed.), Academic Press, p.149-166,1982.

SCHNEIDER, E., KAY, J., Orden a partir del desorden. La termodinámica de la complejidad en Biología, 9 p, 1995. 
SIERRA, M., Aplicación de la transformada de Wavelet continua de dos dimensiones a la detección de Rollos Convectivos Horizontales, Facultad de Matemática Computación, Universidad de La Habana, 60 p, 2008.

STULL, R. B., An Introduction to Boundary Layer Meteorology, Kluwer Academic Press, Dordrecht, The Netherlands, 666 p, 1988.

SUTTON, O., Micrometeorology, McGraw-Hill Book Company, Inc. 333 p, 1953.

VELTISHCHEV, N. F., Mesometeorology and Short-Range Forecasting, Lectures Notes and Student's Workbook for Training Class 1 and Class 2 Meteorological Personal, No 701, Secretariat of the World Meteorological Organization, Geneva, Switzerland, 163 p,1990.
WILSON, J. W., ROBERTS, R. D., Summary of convective storm initiation and evolution during IHOP, Third European Conference on Radar Meteorology (ERAD) in conjunction with $\operatorname{COST} 717,2004$.

WILSON, J. W., SCHREIBER, W. E., Initiation of convective storms at radar-observed boundary-layer convergence lines, Monthly Weather Review, p.2516-2536, 1986.

ZILITITINKEVICH, S. S., MIRONOV, D., A Multi-Limit Formulation for the Equilibrium Depth of a Stably Stratified Boundary Layer, Boundary-Layer Meteorology, p.325351, 1996. 